\title{
Avaliação do conteúdo sobre estrutura interna da Terra em livros didáticos de Geografia do ensino médio de escolas públicas brasileiras
}

\section{Content evaluation on the internal structure of the Earth in high school Geography textbooks from Brazilian public schools}

\author{
Alexandre dos Santos Souza* $\varangle(\mathbb{D}$, Max Furrier $\square(\mathbb{D}$ \\ Departamento de Geociências, Universidade Federal da Paraíba, João Pessoa, Paraíba, Brasil \\ E-mail: max_furrier@hotmail.com \\ *E-mail para correspondência: alesougeo@gmail.com
}

Recebido (Received): 08/12/2019

Aceito (Accepted): 07/04/2020

\begin{abstract}
Resumo: Este trabalho tem por objetivo levantar informações quantitativas e qualitativas, textuais e visuais, visando avaliar como se apresenta o conteúdo sobre "estrutura interna da Terra" em livros didáticos de Geografia da $1^{a}$ série do Ensino Médio, distribuídos pelo Programa Nacional do Livro e do Material Didático (PNLD) às escolas públicas brasileiras para o triênio 2018-2020. Como procedimento metodológico realizou-se uma análise documental de diferentes coleções do guia do PNLD com o propósito de verificar a necessidade de pesquisas que continuem a analisar os conteúdos dos livros didáticos aprovados no referido programa. Dessa forma, considerando a complexidade de trabalhar temas próprios das Ciências da Terra dentro do ensino de Geografia na sala de aula, buscou-se, a partir da análise dos livros didáticos, quantificar e qualificar as informações presentes em 11 coleções, observando se a abordagem sobre o tema em questão fornece subsídios claros e corretos que corroborem positivamente o ensino de Geografia de forma clara e interdisciplinar. O resultado do trabalho demonstrou que nas coleções de livros didáticos selecionados há: notáveis assimetrias entre as informações verbais e não verbais; ausência de autores com formação em Geografia Física e/ou Ciências da Terra; necessidade de correções conceituais; e ausência de aplicações interdisciplinares compatíveis com o nível do público-alvo do Ensino Médio.
\end{abstract}

Palavras-chave: Ensino de Geografia; Ensino de Ciências da Terra; Educação Geográfica; Educação Básica.

Abstract: This work aims to gather quantitative and qualitative, textual and visual information, aiming to evaluate how the content on "Internal Structure of the Earth" is presented in Geography textbooks of the 1st grade of High School, distributed by the National Book and Material Program Didactic (PNLD) to Brazilian public schools for the 2018-2020 period. As a methodological procedure, a documentary analysis of different collections of the PNLD guide was carried out with the purpose of verifying the need for research that continues to analyze the contents of the textbooks approved in that program. Therefore, considering the complexity of working with themes specific to Earth Sciences within the teaching of Geography in the classroom, it was sought, through the analysis of textbooks, to quantify and qualify the information present in 11 collections, observing whether the approach on the subject in question it provides clear and correct subsidies that positively corroborate the teaching of Geography in a clear and interdisciplinary way. The result of the work showed that in the selected textbook collections there are: remarkable asymmetries between verbal and non-verbal information; absence of authors trained in Physical Geography and / or Earth Sciences; need for conceptual corrections; and absence of interdisciplinary applications compatible with the level of the target audience of High School.

Keywords: Geography Teaching; Earth Sciences Teaching; Geography Education; Basic education.

\section{Introdução}

No ensino de Ciências da Terra, o conhecimento da estrutura e características das camadas internas do planeta Terra é um conteúdo abordado dentro do ensino de Geografia na Educação Básica, embora seja 
possível, em virtude das particularidades que envolvem essa temática, abordagens interdisciplinares com outros componentes curriculares, como a "Geologia, Geografia, Biologia, Química e Física" (CARNEIRO; SANTOS, 2012, p. 87). Este trabalho analisa, de maneira particular, como o conteúdo sobre a estrutura Interna da Terra é abordado em livros didáticos de Geografia da $1^{\mathrm{a}}$ série do Ensino Médio distribuídos gratuitamente pelo Programa Nacional do Livro e do Material Didático (PNLD) 2018 às escolas públicas do Brasil.

É importante ressaltar que o conteúdo em questão é de grande relevância para o ensino das propriedades físicas e da dinâmica geológica da Terra, pois, estudando o interior do planeta é possível compreender as composições do Núcleo, Manto e das Crostas, além da dinâmica da Terra através das zonas de convecções. Apesar disso, estudos particularizados que estudam a estrutura Interna da Terra nos livros didáticos são escassos (quando não inexistentes), por isso, emerge a necessidade da realização de trabalhos de cunho acadêmico que analisem não apenas este, mas também outros tópicos de Ciências da Terra presentes em literaturas básicas destinadas ao ensino escolar. Dessa forma, buscou-se avaliar o conteúdo em questão visando identificar se a forma como está apresentado nos livros didáticos favorece uma aprendizagem significativa (MOREIRA; MASINI, 1982) e interdisciplinar (COIMBRA, 2000; GARCIA, 2008).

De acordo com Ernesto et al., (2009), até o fim do século XIX, não havia uma concepção cientificamente bem elaborada da estrutura Interna da Terra. Todavia, com o avanço da ciência no inicio do século XX, trabalhos como o publicado na Alemanha em 1982 pelo sismólogo e professor canadense, Bruce Alan Bolt, intitulado "Inside the Earth" ajudou no desenvolvimento dos princípios da sismologia. No referido trabalho, foi apresentado um modelo (Figura 1) considerado avançado (naquele contexto) para definir as camadas que estruturam o planeta muito próximo dos modelos atualmente empregados, sem, todavia, apresentar os detalhes e características específicas hoje conhecidas devido aos avanços científicos. Dessa forma, as descobertas geofísicas sobre as características do interior da Terra ganharam relevância com o passar tempo, tanto para questões socioeconômicas quanto para o ensino das Ciências da Terra e da própria Geografia.

Partindo desses pressupostos, encontra-se na Geologia uma área do conhecimento direcionado à compreensão da dinâmica de evolução dos materiais que constituem o planeta, no qual ocorrem múltiplas relações com outras áreas das Ciências da Terra. O desafio vai além de procedimentos teóricos metodológicos aplicados visando a classificação e identificação de fatos e fenômenos ocorridos no planeta Terra, por isso, é importante que os conteúdos e os instrumentos de ensino sejam organizados por meio de informações eficazes, evitando, assim, erros, contradições e supressões conforme detalharemos mais adiante.

Sendo assim, ressalta-se a necessidade de estudos pormenorizados (stricto sensu) destinados a examinar como os conteúdos dos aspectos físico-naturais do planeta Terra são apresentados nos livros didáticos de Geografia. No caso particular da temática selecionada neste estudo, é considerada como ponto de partida para outras questões importantes sobre a dinâmica terrestre e, consequentemente, sobre as formas de relevo.

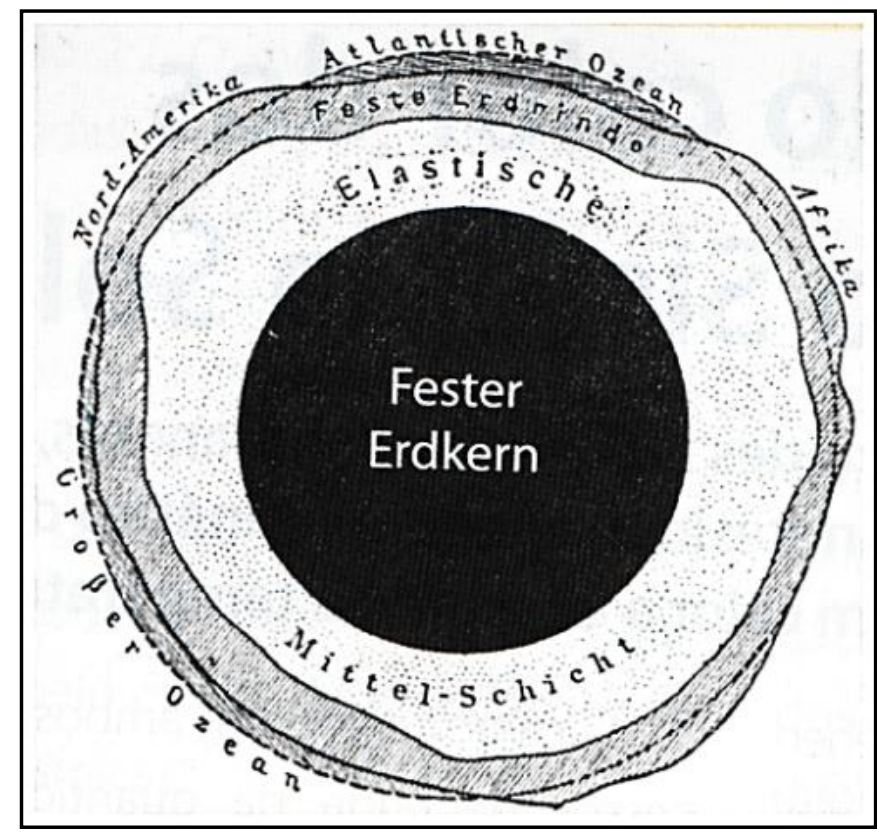

Figura 1: Modelo esquemático da estrutura interna da Terra elaborado no início do século XX. Fonte: Bolt (1982). 
Cabe destacar, também, que no Ensino Médio o componente curricular de Geografia é uma "ponte entre as Ciências Humanas e as Ciências da Natureza" (BRASIL, 2000). No entanto, de acordo com a Base Nacional Comum Curricular (BNCC), a área de Ciências da Natureza e suas Tecnologias é, em tese, aquela que tem por objetivo oportunizar o aprofundamento e a ampliação dos conhecimentos sobre o planeta e o Universo. Já na área de Ciências Humanas, a aprendizagem é direcionada para o desenvolvimento de competências voltadas à interpretação de ideias, pensamentos, fenômenos e processos históricos, geográficos, sociais, econômicos, políticos e culturais (BRASIL, 2017a).

Do ponto de vista da normatização específica prevista na BNCC para a área de Ciências Humanas e Sociais aplicada ao Ensino Médio, não se define categoricamente qualquer exigência dentro das competências específicas e habilidades recomendadas direcionadas ao ensino dos temas ligados à dinâmica da natureza comuns ao ensino de Geografia, configurando-se, assim, uma contradição só justificada quando o documento da BNCC recomenda que sejam efetivadas abordagens interdisciplinares entre as áreas de aprofundamento.

Já nos Parâmetros Curriculares Nacionais para o Ensino Médio (PCNEM), são indicadas "sugestões de organização de eixos temáticos em Geografia", em que a "fisionomia da superfície terrestre" é uma temática sugerida como subtema para iniciar o plano de conteúdos do ensino de Geografia no livro didático da $1^{\mathrm{a}}$ série (BRASIL, 2000, p. 66).

À vista disso, temas particulares de Ciências da Terra necessitam perpassar por uma abordagem cuidadosa, isso porque na Educação Básica o ensino das Ciências da Terra representa uma possibilidade relevante de desenvolvimento de noções práticas de conhecimentos essenciais dos quais o alunado poderá e necessitará utilizar no seu cotidiano. Dessa forma, considerando as orientações propostas no PCNEM, avigora-se a importância de que os livros didáticos ofertados às escolas públicas apresentem possibilidades claras de articulação interdisciplinar entre as áreas de Ciências Humanas e Ciências da Natureza.

Nessa perspectiva, o entendimento dos processos e fenômenos ocorridos na superfície terrestre e das características geológicas, geomorfológicas, climáticas e antropogênicas necessitam de uma abordagem suficientemente capaz de permitir ao alunado compreensão adequada frente às situações de posicionamentos fundamentados em ideias ultrapassadas e no senso comum, levando o aluno a compreender de forma científica, a integração existente entre os subsistemas que formam e configuram as paisagens terrestres.

Destarte, o presente trabalho visa levantar dados quantitativos e qualitativos acerca do conjunto de informações (textuais e visuais) apresentadas sobre a estrutura interna da Terra, averiguando se constam informações precisas, quais as similaridades, se o tema é apresentado de forma clara, quais as fontes mais utilizadas como referencial e se os autores dos livros didáticos avaliados apresentam perfil de formação em Geografia Física ou mesmo nas áreas de Ciências da Terra. Em suma, espera-se que as informações levantadas possam servir para promover outras reflexões sobre a importância e aprimoramento da forma como são expostos os conteúdos dos livros didáticos analisados, bem como, a necessidade de participação de professores especializados em Ciências da Terra na elaboração dos livros.

\section{Sobre a relevância do livro didático}

O surgimento do livro didático está atrelado à criação das escolas nas sociedades se constituindo num agente transmissor de conteúdos que necessitam ser ensinados (SOARES, 1997). Nessa perspectiva, faz-se relevante desenvolver trabalhos que visem ampliar a compreensão do livro didático como um dos principais instrumentos utilizados na condução dos planos de ensino dos conteúdos ministrados na sala de aula.

Para Vesentini (2007) e Andreis e Callai (2009), considerando o livro didático como um elemento capaz de estabelecer um elo importante nas relações do ensino escolar, e o fato de que, no contexto da escolarização brasileira, as aulas continuam seguindo sequências de conteúdos e informações dos livros didáticos ressaltam-se a observância de estudos que avaliem os conteúdos, no caso específico desse trabalho, o estudo da estrutura interna da Terra.

Já Munakata (2016) apresenta o livro didático como um instrumento portador dos saberes escolares importante na cultura escolar. Autores como Vasconcelos e Souto (2003) afirmam que em muitos contextos o livro didático representa o principal - quando não o único - material de suporte didático acessível aos discentes de escolas públicas, representando um recurso estratégico no desenvolvimento das aulas por parte de professores e alunos.

Apesar de ampla maioria de trabalhos destacarem o importante papel e presença do livro didático na Educação Básica, cabe observar o que afirma Castrogiovanni e Goulart (2003), quando ressaltam que entre os instrumentos de ensino oferecidos na escola, o livro didático não deve ser considerado a única fonte de 
transmissão de conhecimento. Nesse sentido quando pensamos em ensino de Geografia, sobretudo aquela direcionada aos discentes do Ensino Básico, é indiscutível a necessidade não apenas do livro didático, mas também de outras literaturas e recursos (trabalhos de campo, aulas práticas, pesquisas, estudos de caso, entre outros), além de infraestrutura e profissionais qualificados.

Outra questão pouco observada, apesar de estar disponível à consulta pública, é a que trata dos recursos financeiros destinados à aquisição dos livros didáticos. Apesar das inúmeras críticas quanto ao modelo e aos valores investidos na Educação Básica, só para ilustrar, tem-se registradas cifras consideráveis direcionadas para aquisição dos livros didáticos no triênio 2017-2019, para o qual, de acordo com o Fundo Nacional de Desenvolvimento da Educação (FNDE), os valores alcançam a cifra de R \$ 3.865.714.794,00, dos quais 38\% foram destinados para aquisição das coleções do Ensino Médio (BRASIL, 2019).

Para todas essas questões supracitadas, é importante que seja um consenso a seguinte prerrogativa: o livro didático não é a única fonte de ensino e deve conter uma linguagem clara, isenta de equívocos e adaptada ao público-alvo, cabendo ao professor nortear possibilidades que estimulem o alunado a aprender de forma cada vez mais significativa.

No caso particular das coleções didáticas distribuídas pelo Ministério da Educação aos alunos da Educação Básica brasileira, sabe-se que a avaliação delas é realizada por meio de uma seleção aberta, com "inscrição de professores de instituições de ensino superior e da educação básica interessados em participar de processos de avaliação educacional no âmbito do Ministério da Educação" (BRASIL, 2017b).

Dessa forma o PNLD 2108 estabelece critérios específicos para avaliação dos livros didáticos de Geografia. Todas as coleções inscritas passam por uma seleção de juízo crítico direcionado a observar pontos comuns em todos os componentes curriculares, além deles, são observados itens específicos de avaliação dos livros didáticos de Geografia, como:

a. atividades referentes aos conteúdos e materiais geográficos que propiciem a interação professor-estudante por intermédio de um diálogo em que sejam possíveis a expressão de significados pelo professor e a ressignificação do conhecimento pelo estudante, com a finalidade de vinculá-lo à prática social;

b. coerência e adequação metodológicas internas entre os livros da coleção, tanto no que se refere à linha de pensamento geográfico adotada, quanto à orientação pedagógica;

c. os conteúdos e conceitos geográficos aceitos pela comunidade científica e aplicados a todas as regiões do país, demonstrando conhecimento atualizado dos avanços teóricos e das pesquisas publicadas na área;

d. conceitos a partir dos processos, dinâmicas e fenômenos, em suas relações espaçotemporais;

e. conceitos e informações apresentados de forma errada ou confusa, dificultando os relacionamentos próprios da análise geográfica da realidade;

f. informações corretas e atualizadas que demonstrem o embasamento teórico-metodológico adotado;

g. mapas, gráficos e tabelas utilizando a linguagem cartográfica, localizando corretamente a informação geográfica no espaço e no tempo e articulando diferentes escalas geográficas;

h. isenção de qualquer tipo de doutrinação (religiosa, política), bem como de preconceitos, como os de origem, condição socioeconômica, etnia, gênero, religião, idade, orientação sexual ou outras formas de discriminação, seja nos textos, seja nas ilustrações;

i. isenção de marcas, símbolos ou outros identificadores de corporações ou empresas, a não ser quando se mostrarem necessários para explicar os processos espaciais. (BRASIL, 2017b, p. 17, grifo nosso)

\section{Procedimentos metodológicos}

A metodologia utilizada se fundamentou na organização e sistematização de procedimentos desenvolvidos em etapas definidas, conforme proposta de Libault (1971), entre as quais foram aplicadas: coleta e compilação de dados pertinentes à pesquisa; formulação de comparações das informações, visando estabelecer correlações significativas ao desenvolvimento do trabalho; e elaboração de dados que favoreçam avaliar com detalhe o teor das informações sobre o tema estudado.

Além disso, buscou-se subsidiar a fundamentação teórica do trabalho a partir de uma pesquisa bibliográfica, buscando obras e trabalhos que alicerçasse as hipóteses alçadas; e documental, por meio da análise direta do tema abordado nos livros didáticos selecionados. De acordo com Gil (2008) e Bardin (1977), esse procedimento é fundamental para o desenvolvimento de trabalhos que buscam levantar dados que auxiliem a investigação e permitam uma exposição objetiva e sistemática do objeto analisado. Seguindo 
essa linha, Prodanov e Freitas (2013) indicam meios científicos à pesquisa mediante uma abordagem aplicando métodos estatísticos que possam auxiliar nas formulações de hipóteses e fornecer resultados importantes sobre o tema estudado.

Neste sentido, o presente trabalho se estrutura numa abordagem direcionada aos livros didáticos de Geografia da $1^{\mathrm{a}}$ série do Ensino Médio disponibilizados pelo PNLD 2018 - especificamente o tópico que trata do estudo da estrutura interna da Terra - investigando se apresentam informações corretas, pertinentes e suficientes para auxiliar professores e alunos a contextualizarem e compreenderem as questões acerca desta temática.

Para tanto, foram observados de forma criteriosa os textos verbais e não verbais (desenhos esquemáticos), identificando-se as similaridades, contradições e se a forma de abordagem da temática corrobora a possibilidade de uma aprendizagem significativa que não seja organizada apenas por intermédio de exposições conteudista. Para tanto, buscou-se, nos livros didáticos de Geografia do PNLD (Tabela 1), levantar dados sobre pontos de concordância, contraditórios e insuficientes no que tange à apresentação do tema escolhido.

Tabela 1: Livros didáticos da $1^{a}$ série do Ensino Médio ofertados pelo PNLD 2018.

\begin{tabular}{|c|c|c|c|c|}
\hline LD & Título & Autores & Editora & Ano/Edição \\
\hline 1 & Ser Protagonista Geografia ${ }^{(1)}$ & $\begin{array}{l}\text { Bianca Carvalho Vieira; Carla Bilheiro Santi; Carlos } \\
\text { Henrique Jardim; Fernando dos Santos Sampaio; Flávio } \\
\text { Manzatto de Souza; Ivone Silveira Sucena; André } \\
\text { Baldraia. }\end{array}$ & SM & $2016-3^{a}$ \\
\hline 2 & Geografia - Contextos e Redes & Angela Corrêa Da Silva; Nelson Bacic Olic; Ruy Lozano. & Moderna & $2016-2^{a}$ \\
\hline 3 & Geografia Geral e do Brasil & Eustáquio De Sene; João Carlos Moreira. & Scipione & $2016-3^{a}$ \\
\hline 4 & Geografia no Cotidiano & Dadá Martins; Francisco Bigotto; Márcio Vitiello. & $\begin{array}{c}\text { Base } \\
\text { Editorial }\end{array}$ & $2016-1^{\mathrm{a}}$ \\
\hline 5 & Geografia: Leituras e Interação & Antonio Luís Joia; Arno Aloísio Goettems. & Leya & $2016-2^{a}$ \\
\hline 6 & Geografia - Espaço e Identidade & Andressa Alves; Levon Boligian. & Do Brasil & $2016-1^{a}$ \\
\hline 7 & Geografia em Rede & Edilson Adão; Laercio Furquim Jr. & FTD & $2016-2^{a}$ \\
\hline 8 & Fronteiras da Globalização & Lúcia Marina Alves de Almeida; Tércio Barbosa Rigolin. & Ática & $2016-3^{a}$ \\
\hline 9 & Geografia das Redes & Douglas Santos. & Do Brasil & $2016-3^{\mathrm{a}}$ \\
\hline 10 & $\begin{array}{l}\text { Território e Sociedade no Mundo } \\
\text { Globalizado }\end{array}$ & $\begin{array}{l}\text { Anselmo Lazaro Branco; Cláudio Mendonça; Elian Alabi } \\
\text { Lucci. }\end{array}$ & $\begin{array}{c}\text { Saraiva } \\
\text { Educação }\end{array}$ & $2016-3^{a}$ \\
\hline 11 & $\begin{array}{l}\text { Conexões - Estudos de } \\
\text { Geografia Geral e do Brasil }\end{array}$ & Lygia Terra; Raul Borges Guimarães; Regina Araujo. & Moderna & $2016-3^{a}$ \\
\hline
\end{tabular}

${ }^{(1)}$ Única coleção que declarou possuir autor com formação em Geografia Física.

Nota: No PNLD - 2018 foram aprovadas 14 coleções de livros didáticos. Não foi possível aquisição das versões impressas dos seguintes livros que compõem o PNLD: Vivá - Geografia, editora Positivo - 1a edição/2016; Geografia - ação e transformação, editora Escala Educacional - $1^{a}$ edição/2016; \#Contato Geografia, editora Quinteto - $1^{\mathrm{a}}$ edição/2016. Os referidos livros só foram encontrados em versões digitais, por isso, opto-se por avaliar apenas os livros adquiridos na versão impressa. Fonte: Brasil (2017b).

\section{Resultados e discussões}

Visando identificar inicialmente as principais características do tópico que aborda a estrutura interna da Terra, foi elaborado um questionário (Tabela 2), a partir do qual foram obtidos dados que contribuíram para o detalhamento do perfil das informações presentes nos livros didáticos (LDs).

Uma questão importante, pouco evidente nos livros estudados, foi o aspecto da abordagem interdisciplinar no conteúdo avaliado. De acordo com Japiassu (1976) a interdisciplinaridade representa a busca por uma metodologia de ensino que institua, na prática de ensino, a interação entre as diversas ciências, visando alicerçar o conhecimento e ampliar as possibilidades de aprendizagem significativa e integrada com as necessidades e realidades do mundo. Nesse sentido, observou-se que tal característica é inexistente na maioria das coleções. Outra peculiaridade observada foi a assimetria dos dados e as informações imprecisas sobre a diferenciação entre as camadas internas da Terra, conforme será detalhado mais adiante. 
Tabela 2: Levantamento das informações sobre a estrutura interna da Terra apresentadas nos LDs

Informações sobre a estrutura interna da

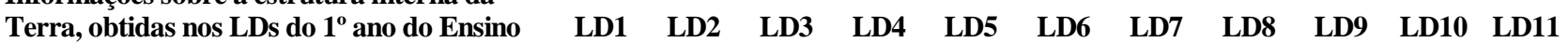
Médio

\begin{tabular}{|c|c|c|c|c|c|c|c|c|c|c|c|}
\hline Capítulo que abordam o tema & 6 & 5 & 5 & 5 & 4 & 13 & 5 & 6 & 3 & 4 & (1) \\
\hline $\mathrm{N}^{\mathrm{o}}$ de páginas que abordam o tema & 2 & 3 & 1 & 3 & 3 & 3 & 2 & 2 & 2 & 2 & (1) \\
\hline Apresenta desenhos esquemáticos? & Sim & Sim & Sim & Sim & Sim & Sim & Sim & Sim & Sim & Sim & (1) \\
\hline Faz abordagem interdisciplinar? & Não & Sim & Não & Sim & Sim & Sim & Não & Não & Não & Não & (1) \\
\hline $\begin{array}{l}\text { Explica como se formaram as camadas da } \\
\text { estrutura interna da Terra? }\end{array}$ & Sim & Sim & Não & Sim & Sim & Não & Não & Sim & Não & Não & (1) \\
\hline Constam informações incoerentes? & Não & Não & Sim & Sim & Não & Sim & Sim & Não & Sim & Sim & (1) \\
\hline $\begin{array}{l}\text { Explica como é possível definir as camadas } \\
\text { internas da Terra? }\end{array}$ & Não & Sim & Não & Não & Sim & Sim & Sim & Não & Não & Sim & (1) \\
\hline $\begin{array}{l}\text { Propõe atividades para elaboração de maquetes } \\
\text { ou modelos escalares? }\end{array}$ & Sim & Não & Não & Não & Não & Não & Não & Não & Não & Não & (1) \\
\hline Aborda questões de vestibulares e Enem? & Não & Sim & Não & Não & Sim & Não & Não & Não & Não & Não & $(1)$ \\
\hline
\end{tabular}

(1) Nota. O LD 11 foi analisado seguindo o mesmo critério dos demais, no entanto no mesmo, não constam imagens e abordagens direcionadas ao ensino das características da estrutura interna da Terra (nos capítulos 9 e 10) onde se deveria haver alguma citação sobre o conteúdo em questão.

\subsection{Interdisciplinaridade no Ensino de Geociências: como se apresenta o tópico sobre a estrutura interna da Terra?}

Os conhecimentos sobre Geociências não devem estar restritos apenas ao universo acadêmico, afinal, nem todo cidadão buscará profissionalização (técnica e/ou científica) em conhecimentos próprios das Ciências da Terra. Mesmo assim, considerando as implicações das circunstâncias dos impactos que envolvem muitos problemas que afetam a sociedade humana em diferentes escalas, na medida em que as pessoas se apropriam e ocupam as paisagens terrestres, torna-se cada vez mais necessário que, na escola, sejam criados meios e espaços próprios para construção de aprendizados que permitam aos educandos desenvolverem habilidades e competências.

No caso do ensino de Geociências abordado dentro do componente curricular de Geografia a partir dos livros didáticos da $1^{\text {a }}$ série do Ensino Médio, é importante estar atento para que o aprofundamento de conceitos científicos não seja transmitido por meio de formas rígidas e de modelos complexos e meramente ilustrativos, sem conexão como a realidade prática do cotidiano do alunado. Nessa perspectiva, Toledo (2005) destaca que na abordagem dos temas geocientíficos, os autores e instrumentos devem evitar abordagens desconexas, fragmentadas ou direcionadas à formação de habilidades técnicas.

Com relação à forma como é apresentada a temática sobre a estrutura interna da Terra, foi observado que é utilizado majoritariamente o recurso de representação de desenhos esquemáticos (com exceção do LD11) (Tabela 3). Para fins didáticos, os desenhos esquemáticos possuem um potencial interessante de representação de estruturas geológicas e paisagens geomorfológicas, e quando utilizados da forma correta podem facilitar o ensino de Geografia.

Tabela 3: Dados sobre a espessura da Crosta terrestre apresentados nos livros didáticos do $1^{\circ}$ ano do Ensino Médio ofertados pelo PNLD 2018

\begin{tabular}{|c|c|c|c|c|}
\hline \multirow{2}{*}{ Livro Didático } & \multicolumn{3}{|c|}{ Espessura da Crosta } & \multirow{2}{*}{ Página } \\
\hline & Continental & & Oceânica & \\
\hline LD1 & & 0 a $40 \mathrm{~km}^{(1)}$ & & 81 \\
\hline LD2 & 30 a $50 \mathrm{~km}$ & & Até $6 \mathrm{~km}$ & 105 \\
\hline LD3 & 25 a $70 \mathrm{~km}$ & & 6 a $12 \mathrm{~km}$ & 112 \\
\hline LD4 & Até $70 \mathrm{~km}$ & & Até $40 \mathrm{~km}$ & 102 \\
\hline LD5 & 30 a $70 \mathrm{~km}$ & & 6 a $7 \mathrm{~km}$ & 80 \\
\hline LD6 & Até $70 \mathrm{~km}$ & & $7,5 \mathrm{~km}$ & 204 \\
\hline LD7 & & 5 a $80 \mathrm{~km}^{(1)}$ & & 109 \\
\hline LD8 & & Não mensurada & & 74 \\
\hline LD9 & & 6,3 a $35 \mathrm{~km}^{(1)}$ & & 61 \\
\hline LD10 & 20 a $70 \mathrm{~km}$ & & 5 a $15 \mathrm{~km}$ & 61 \\
\hline LD11 & & Sem detalhamento & & - \\
\hline
\end{tabular}


Observa-se a partir do levantamento das informações compiladas sobre as figuras usadas nos livros didáticos para abordagem conceitual sobre a estrutura interna da Terra (Tabela 3) que não há um consenso sobre as características (espessura e diferenciação) da crosta terrestre, camada importante para o ensino de Geografia, pois, é nessa camada onde ocorrem fenômenos e processos atrelados à construção das paisagens e do espaço geográfico.

Outra questão importante que deve ser observada é a relação entre o livro didático de Geografia com conteúdos que são próprios das Ciências da Natureza. Essa questão requer atenção especial, pois, conforme dito anteriormente, nos PCNEM essa é uma oportunidade de promover o ensino interdisciplinar, que é fundamental no planejamento didático do conteúdo programático de uma ciência humana dotada de ampla abrangência, como é o caso da Geografia (BRASIL, 2000).

Assim sendo, tópicos de Geociências como o estudo da estrutura interna da Terra, quando abordados dentro do livro didático de Geografia, devem ser tratados como conteúdos importantes, pois servem como ponto de partida para o ensino de diversas outras temáticas. Por isso, destaca-se a proposição de Pontuschka et al. (2009), quando afirmam que a interdisciplinaridade não é a mera junção de saberes, mas sim uma forma mais eficiente de abordar temas relevantes ao conhecimento, neste caso em particular, aqueles relacionados ao entendimento da dinâmica terrestre.

Cabe destacar que a interdisciplinaridade também está prevista nos PCNEM (BRASIL, 2000) como forma de superar propostas e práticas fragmentadas de ensino entre os diversos saberes. Sobre isso, Almeida et al. (2015) comentam que a questão interdisciplinar é crucial no desenvolvimento de uma aprendizagem mais significativa.

Atento ao tratamento das informações dos conteúdos presentes nos livros didáticos, Mendonça (1992, p. 44) comenta o fato de muitos trabalhos que abordam os aspectos básicos da Geografia estarem vinculados à "autoria de geógrafos ligados principalmente à parte humana/social da Geografia, registrando uma tendência de tratar os aspectos ligados à Geografia Física de maneira muito superficial”.

É importante ressaltar, neste ponto, que não se pretende questionar a aptidão dos autores (não é este o cerne da pesquisa). No entanto, uma observação preliminar dos currículos acadêmicos dos autores que assinam as coleções (vide nomes na Tabela 1) comprova a alegação de Mendonça (1992), quando se tem um número de autores majoritariamente formados em Geografia Humana, sem titulação acadêmica na área da Geografia Física ou em Geociências.

Nesse sentido, ressalta-se a importância de que haja, entre os envolvidos na confecção dos livros didáticos, profissionais com know-how em todas as áreas contempladas no compêndio dos conteúdos, quer sejam das áreas das Ciências Humanas e Sociais ou mesmo das áreas das Ciências Exatas e da Natureza.

Outra questão importante é posta por Almeida et al. (2015), que ressalvam a importância da participação da Geologia no ensino escolar, alertando para o fato de que, em muitos casos, a abordagem feita sobre os conteúdos dessa ciência tem origem em trabalhos realizados no meio acadêmico, e que os livros didáticos adotados nas escolas seguem, no geral, uma linha de elaboração fundamentada com exemplos e ilustrações da Geologia global.

Portanto, no que tange o ensino dos temas ligados às Ciências da Terra, observa-se que os mesmos, devem sim ser apresentados, entretanto, é importante que tais informações não sejam destoantes de uma coleção didática para outra, principalmente quando forem utilizadas as mesmas fontes paradidáticas, conforme observado na caracterização da Crosta Terrestre apresentada nos livros didáticos (detalhada acima na Tabela 3) e observados nos desenhos esquemáticos (Figura 2) e na Tabela 4 onde se nota maior participação de citações bibliográficas dos livros Para entender a Terra e Decifrando a Terra. 


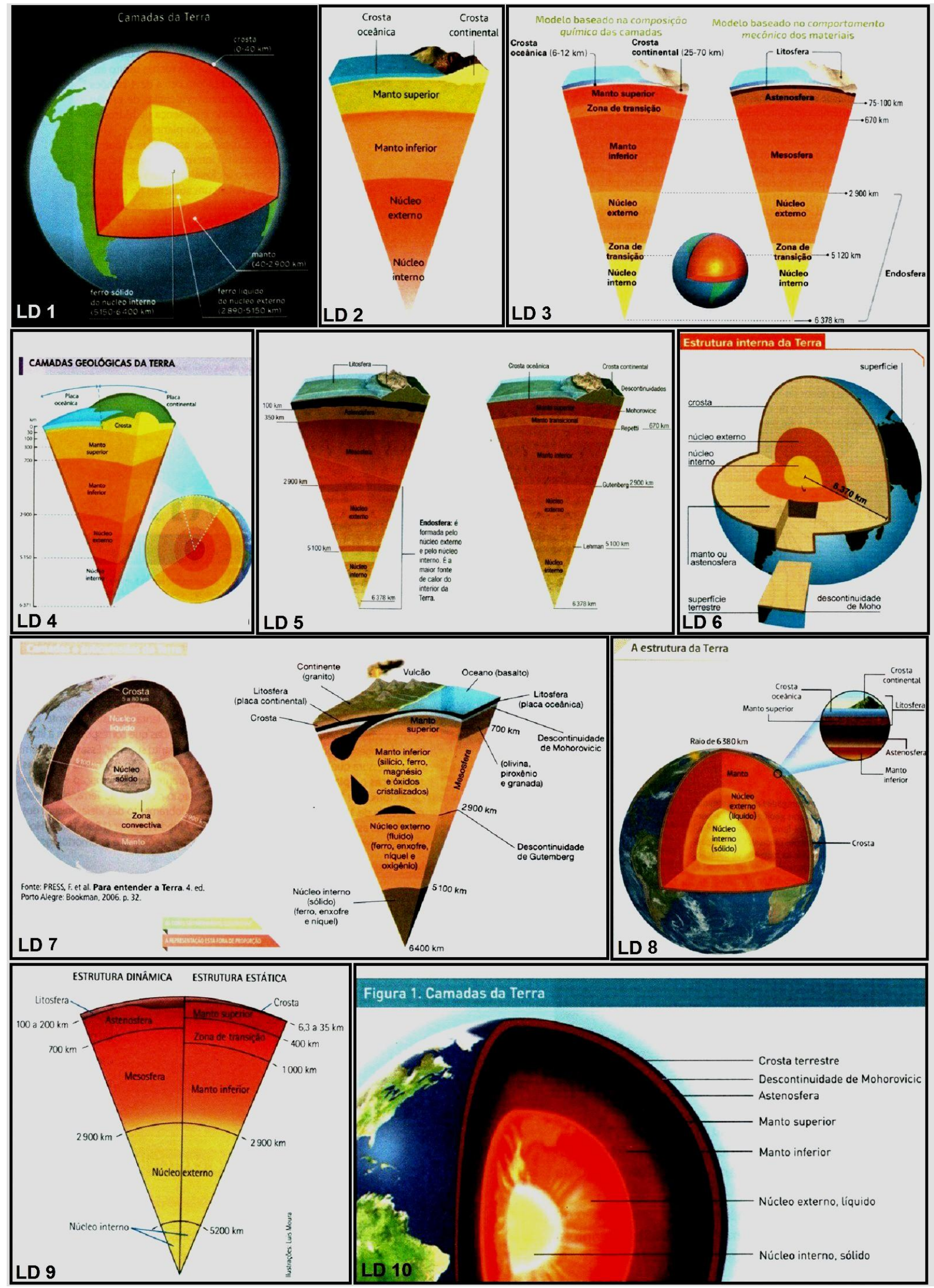

Figura 2: Principais desenhos esquemáticos apresentados nos livros didáticos. 
Tabela 4: Fontes bibliográficas das imagens usadas para ilustrar a estrutura interna da Terra

\section{Livro Didático}

Fonte das Imagens

LD1 PRESS, Frank et al. Para entender a Terra. 4. ed. Porto Alegre: Bookman, 2006. p. 32. PETERSEN, James F.; SACK, Dorothy; GABLE, Robert E. Fundamentos de Geografia Física. São Paulo: Cengage Learning, 2014. p. 241

LD2 PRESS, Frank et al. Para entender a Terra. Porto Alegre: Bookman, 2008. p. 56.

LD3 Adaptado de ENCICLOPÉDIA do estudante: ciências da Terra e do Universo. São Paulo: Moderna, 2008. p. 23.

LD4 TEIXEIRA, Wilson et al. (Orgs.). Decifrando a Terra. São Paulo: Oficina de Textos, 2008. p. 85.

LD5 Adaptado de TEIXEIRA, Wilson et al. (Orgs.). Decifrando a Terra. São Paulo: Companhia Editora Nacional, 2009. p. 71.

LD6 CALDINI, Vera; ÍSOLA, Leda. Atlas geográfico Saraiva. São Paulo: Saraiva, 2013. p.18. LEINZ, Viktor; AMARAL, Sergio Estanislau. Geologia Geral. São Paulo: Companhia Editora Nacional, 2003. p. 321.

LD7 SUGUIO, Kenitiro; SUZUKI, Uko. A evolução geológica da Terra e a fragilidade da vida. São Paulo: Edgard Blücher, 2003. p. 13.

LD8 Adaptado de ATLANTE geografico metódico De Agostini. Novara: Instituto Geografico De Agostini 2015. p. 10-11.

LD9 MOLINA, Eder Cassola (Coord.). Investigando a Terra. São Paulo: USP, 1997. Disponível em: https://www.iag.usp.br/siae97/geofs/terra0.htm.

LD10 CALDINI, Vera; ÍSOLA, Leda. Atlas geográfico Saraiva. São Paulo: Saraiva, 2007. p. 20.

LD11 (Não apresenta ilustração nem dados).

\subsection{Localização das incoerências encontradas}

Não obstante a função e importância do livro didático no processo de ensino-aprendizagem ressalta-se que quando ocorrem disparidades acentuadas, erros, omissões ou tratamento superficial das informações conceituais necessárias na abordagem de um tema, tem-se configurada uma situação que comprometerá o sentido e o resultado final do objetivo proposto dentro das prerrogativas de desenvolvimento das habilidades e competências almejadas. Dessa forma, analisando as informações alçadas, pode-se inferir qualitativamente sobre alguns aspectos que devem ser retificados, conforme se discorrerá a seguir.

No LD3, no LD7 e no LD10, o manto terrestre é caracterizado de forma equivocada. Estudos atestam que "o manto, a despeito de sua temperatura maior, está submetido a uma pressão tão alta que faz com que seja pouco plástico e totalmente sólido" (ERNESTO et al., 2009, p. 74). Tal definição contrasta com as apresentadas no LD3, quando os autores afirmam que essa camada é formada por "magma pastoso" (Figura 3). Um erro semelhante é cometido no LD7, quando os autores indicam que a astenosfera é "uma camada mais pastosa, na qual a crosta continental flutua" sem destacar também que a crosta oceânica (ou seja, o conjunto de placas litosféricas) está assentada sobre a astenosfera. No LD10 é apresentado o entendimento de que o manto e a camada correspondente à astenosfera formam uma camada constituída por "magma" (Figura 3), contrariando outras fontes bibliográficas especializadas publicadas por autores como Suguio (1998) e Press et al. (2008), os quais foram usados como fonte dos desenhos esquemáticos apresentados na página 109 do LD10.

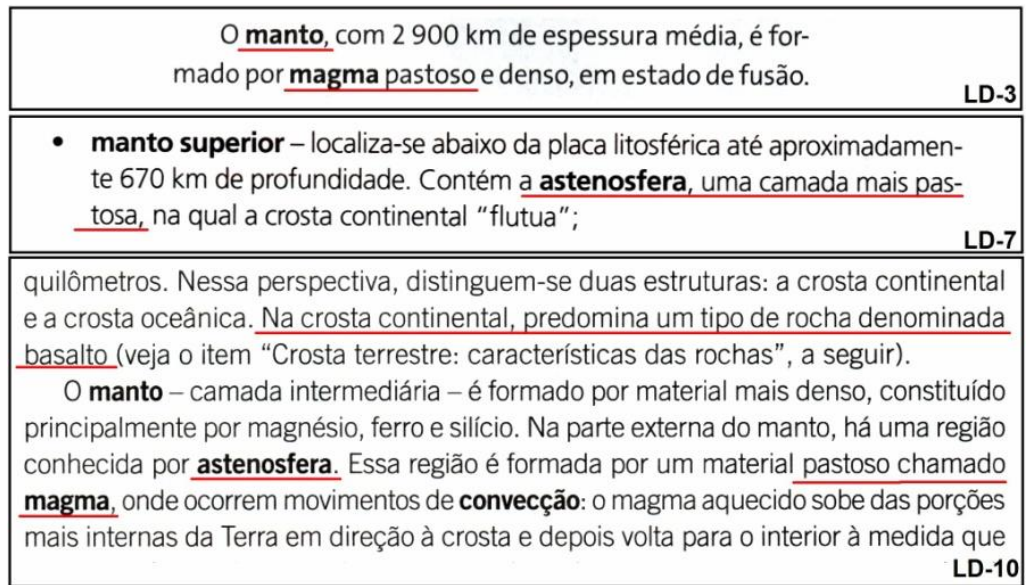

Figura 3: Erros conceituais cometidos na caracterização do manto da Terra. 
No LD6, faz-se necessária uma correção na página 203, onde os autores dizem que o manto terrestre é "também chamado de astenosfera" (Figura 4a), divergindo dos conceitos apresentados em obras de Guerra e Guerra (1997), Suguio (1998) e Ernesto et al. (2009), onde se define a astenosfera (zona do manto terrestre que se inicia entre 50 a $100 \mathrm{~km}$ abaixo e se estende até cerca de $500 \mathrm{~km}$ ) como uma camada onde ocorrem os movimentos plásticos nos quais as placas litosféricas (constituídas pela crosta e uma pequena porção do manto superior) se movimentam e que se difere do restante do manto inferior, principalmente pelas propriedades físicas dos materiais constituintes, espessura. Além disso, o desenho esquemático apresentado no LD6 não contribuiu para explicar visualmente a diferenciação apresentada no texto sobre o manto superior (onde se localiza a astenosfera) e o manto interior (Figura 4a).

Outra constatação sobre informações equivocadas está contida no LD9, quando os autores apresentam no desenho esquemático (Figura 4b) as seguintes informações contraditórias: $1^{\mathbf{a}}$ ) "Na área da Cordilheira dos Andes", a litosfera "mergulha no mineral liquido, provocando terremotos e vulcões", tal afirmação não está devidamente correta, pois é comprovado que os fenômenos endógenos citados são desencadeados pela colisão entre a crosta continental e crosta oceânica, que, inclusive, provoca o soerguimento de cordilheiras, quando a crosta oceânica (mais densa) mergulha sob a crosta continental (menos densa) entrando em fusão parcial na medida em que atinge maior profundida; $2^{\mathrm{a}}$ ) na mesma imagem há uma indicação de que a astenosfera é uma camada "formada por minerais ainda em estado líquido", entretanto, estudos têm comprovado que o magma (material pastoso) não constitui a astenosfera em sua totalidade, mas sim, "hot spots ou pontos quentes" situados em diversas profundidades no limite entre o núcleo externo e o manto inferior. Os hot spots formam plumas estacionárias no manto, cuja maior evidência são as marcas deixadas pela atividade vulcânica na superfície da crosta terrestre conforme apresentado por Tassinari e Dias Neto (2009) no livro "Decifrando a Terra" na página 98.

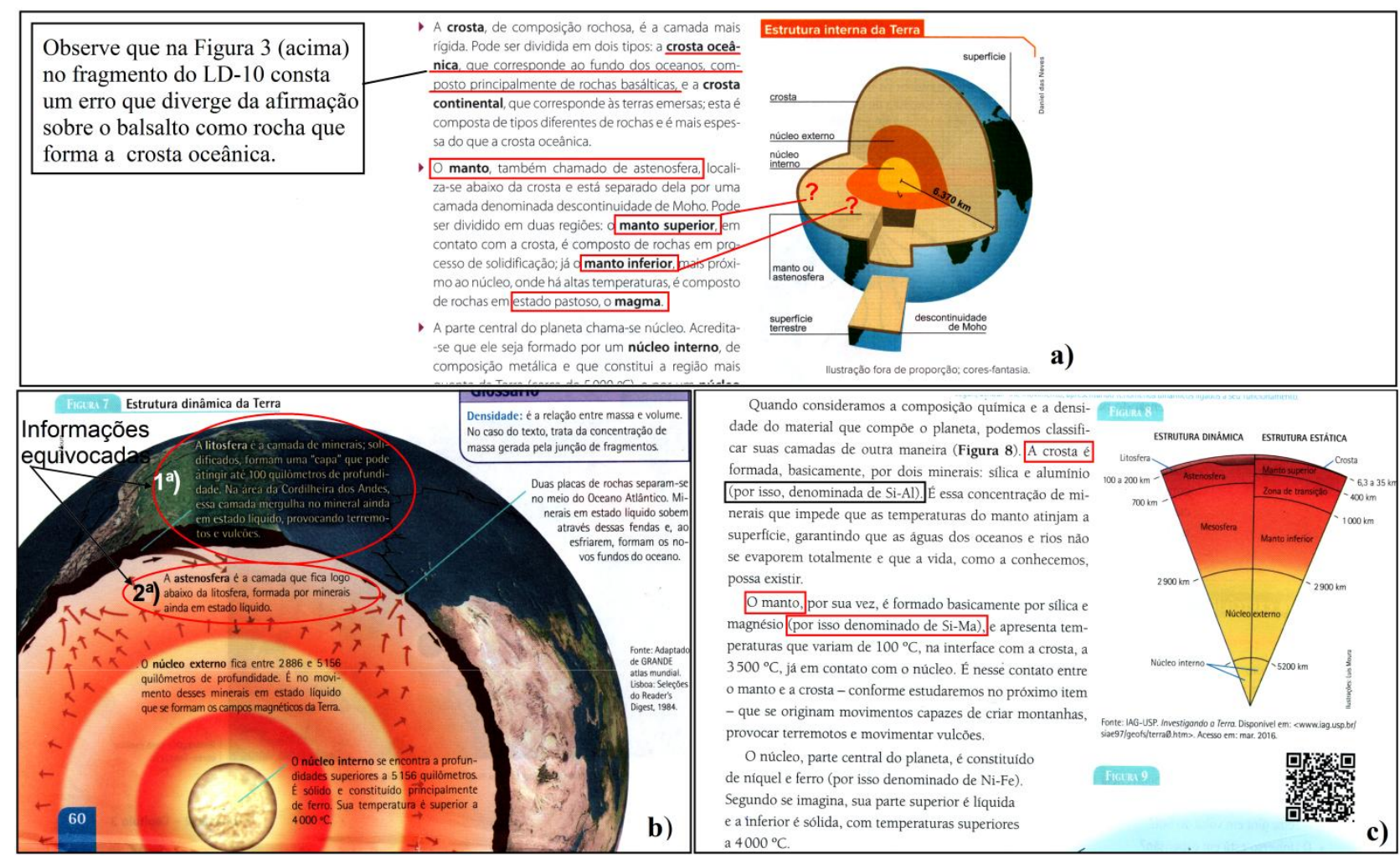

Figura 4: Informações apresentadas de forma equivocada.

Na página 61 do LD9 ocorre outra informação de forma imprecisa, quando é atribuída a denominação de "Si-Al" (silício e alumínio) para crosta sem especificar que essa atribuição geoquímica é comumente usada para a crosta continental, e Si-Ma (silício e magnésio) para crosta oceânica (Figura 4c). No mesmo texto os autores definem "Si-Ma" como uma definição para o manto terrestre, sendo que nenhuma literatura especializada classifica o manto com essa denominação. 


\section{Considerações finais}

Nessa perspectiva, ressalta-se a importância de trabalhos que avaliem se os conteúdos apresentados nos livros didáticos da Educação Básica brasileira são organizados de forma interdisciplinar, se distanciando abordagens meramente descritivas dos aspectos físico-naturais do planeta. Nesse sentido, os materiais didáticos (não apenas os livros de Geografia) destinados às escolas devem nortear de maneira efetiva e isenta de equívocos as possibilidades de ensino.

Outro ponto importante é a necessidade da presença do estudo dos conteúdos de Ciências da Terra no livro didático de Geografia da Educação Básica, bem como a observância se os mesmos são apresentados nos livros de maneira coerente e com a devida pertinência. Entretanto, ressalta-se que nenhum dos livros, tampouco os meios de elaboração e escolha desses instrumentos, são infalíveis, por isso, busca-se incentivar, com este trabalho, pesquisas que observem detalhadamente o teor e a diagramação de cada temática, fornecendo dados que possam contribuir com ajustes dos conteúdos disponibilizados nos materiais para professores e alunos na Educação Básica. Quanto aos erros conceituais, uma medida adequada seria (além dos ajustes e correções dos equívocos), as editoras agregarem entre os elaboradores, consultores que possam assessorar na abordagem de alguns conhecimentos mais específicos que porventura fujam à formação dos autores.

A proposta de trabalho desenvolvida aqui se ampara no princípio de que quando se discute sobre ensino e aprendizagem de temas transversais, como é o caso das Ciências da Terra, é praticamente unânime a premissa que defende a necessidade de integração dos saberes para uma aprendizagem mais significativa. Por isso, em relação às leis que tentam dar um direcionamento aos conteúdos desenvolvidos nas escolas, particularmente nos PCNEM, a interdisciplinaridade tem sido proposta como forma de minimizar a fragmentação entre os diversos saberes e tentar maior aproximação e compreensão à complexa realidade do mundo atual, prerrogativa que em muitos casos não foi contemplada, pelo menos no que diz respeito ao tema sobre a estrutura interna da Terra.

Além disso, é de suma importância que os investimentos feitos nos materiais didáticos, nesse caso, os livros de Geografia do $1^{\circ}$ ano do Ensino Médio, sejam destinados à aquisição de produtos bem ajustados à realidade do alunado. Nesse sentido, os conteúdos de temáticas físico-naturais trabalhadas no ensino de Geografia devem ser apresentados sem equívocos, visando promover o ensino com eficácia, uma vez que avigora-se cada vez mais a necessidade de preparar a sociedade para agir diante de questões ambientais cuja dinâmica tem afetado a vida das pessoas.

\section{Referências}

ALMEIDA, C. N.; ARAÚJO C.; MELLO E. F. Geologia nas escolas de Ensino Básico: a experiência do Departamento de Geologia da Universidade Federal do Rio de Janeiro. Terræ Didatica, v. 11, n. 3, p. 150161, 2015. https://doi.org/10.20396/td.v11i3.8643643

ANDREIS, A. M., CALLAI, H. C. Alicerces às aulas: princípios, conceitos e categorias geográficas. Revista Ensino de Geografia (Recife), V. 2, No. 3, 2019. https://doi.org/10.38187/regeo2019.v2n3id243921

BARDIN, L. Análise de conteúdo. Lisboa: Edições 70, 1977.

BOLT, B. A. Inside the Earth. San Francisco: W. H. Freeman \& Co., 1982.

BRASIL. Ministério da Educação. Programas do livro: PNLD - dados estatísticos. Brasília: MEC/SEB/FNDE, 2019. Disponível em: https://www.fnde.gov.br/index.php/programas/programas-dolivro/pnld/dados-estatisticos. Acesso em: 15 nov. 2019.

BRASIL. Ministério da Educação. Base Nacional Comum Curricular: Educação é a Base: Ensino Médio. Brasília: MEC/SEB, 2017a. Disponível em: https://edisciplinas.usp.br/mod/resource/view.php?id=2376745. Acesso em: 15 nov. 2019.

BRASIL. Ministério da Educação. PNLD 2018: Geografia - guia de livros didáticos - Ensino Médio. Brasília: MEC/SEB/FNDE. 2017b. 
BRASIL. Ministério da Educação. PCN+ Ensino Médio: orientações educacionais complementares aos Parâmetros Curriculares Nacionais - Ciências Humanas e suas tecnologias. Brasília: MEC/SEB, 2000. Disponível em: http://portal.mec.gov.br/seb/arquivos/pdf/CienciasHumanas.pdf. Acesso em: 15 nov. 2019.

CARNEIRO, C. D. R.; SANTOS, G. R. B. Ensino de Geociências na formação profissional em meio ambiente no estado de São Paulo. Revista Brasileira de Geociências, v. 42, Suplemento 1, p. 84-95, 2012.

CASTROGIOVANNI, A. C.; GOULART, L. B. A questão do livro didático em Geografia: elementos para uma análise. In CASTROGIOVANNI, A. C.; CALlAI, H. C.; SCHAFFER, N. O.; KAERCHER, N. A. (Orgs.). Geografia em sala de aula: práticas e reflexões. 4. ed. Porto Alegre: Mediação, 2003. p. 133-171.

COIMBRA, J. A. A. Considerações sobre a interdisciplinaridade. In PHILIPPI JR., A. Interdisciplinaridade em Ciências Ambientais. São Paulo: Signus, 2000, p. 52-70.

ERNESTO, M.; MARQUES, L. S.; MCREATH, I.; USSAMI, N.; PACCA, I. I. G. O interior da Terra. In TEIXEIRA, W.; FAIRCHILD, T. R.; TOLEDO M.C.M.; TAIOLI, F. (Orgs.). Decifrando a Terra; 2. ed. São Paulo: Companhia Editora Nacional, 2009. p. 50-78.

GARCIA, J. A Interdisciplinaridade segundo os PCNs. Educação Pública, v. 17 n. 35, p. 363-378, 2008. https://doi.org/10.29286/rep.v17i35.494

GIL, A. C. Métodos e técnicas de pesquisa social. 6. ed. São Paulo: Atlas, 2008.

GUERRA, A. T.; GUERRA, A. J. T. Novo dicionário geológico-geomorfológico. Rio de Janeiro: Bertrand Brasil, 1997.

JAPIASSÚ, H. Interdisciplinaridade e patologia do saber. Rio de Janeiro: Imago, 1976.

LIBAULT, A. Os quatro níveis da pesquisa geográfica. Métodos em Questão, n. 1, p. 1-14, 1971.

MENDONÇA, F. Geografia Física: ciência humana? 3. ed. São Paulo: Contexto, 1992.

MOREIRA, M. A.; MASINI, E. A. F. S. Aprendizagem significativa: a teoria de David Ausubel. São Paulo: Moraes, 1982.

MUNAKATA, K. Livro didático como indício da cultura escolar. História da educação, v. 20, n. 50, p. 119-138, 2016. http://dx.doi.org/10.1590/2236-3459/624037

PONTUSCHKA, N. N.; PAGANELLI, I. T.; CACETE, H. N. A interdisciplinaridade e o ensino de Geografia. In PONTUSCHKA, N. N.; PAGANELLI, I. T.; CACETE, H. N. Para ensinar e aprender Geografia. 3. ed. São Paulo: Cortez, 2009.

PRODANOV, C. C.; FREITAS, E. C. Metodologia do trabalho científico: métodos e técnicas da pesquisa e do trabalho acadêmico. 2. ed. Novo Hamburgo: Feevale, 2013.

SOARES, M. B. Livro didático: uma história mal contada. Moderna OnLine - Fazendo Escola. São Paulo, ago. 1997. Disponível em: https://www.moderna.com.br/escola/prof/art02.html. Acesso em: 22 abr. 2001.

SUGUIO, K. A. Dicionário de Geologia Sedimentar e áreas afins. Rio de Janeiro: Bertrand Brasil, 1998.

TASSINARI, C. C. G.; DIAS NETO, C. M. Tectônica global. In TEIXEIRA, W.; FAIRCHILD, T. R.; TOLEDO M. C. M.; TAIOLI, F. (Orgs.). Decifrando a Terra. 2. ed. São Paulo: Companhia Editora Nacional, 2009. p. 78-107.

TOLEDO, M. C. M. Geociências no Ensino Médio brasileiro: análise dos Parâmetros Curriculares Nacionais. Geologia USP Publicação Especial, n. 3, p. 31-44, 2005. https://doi.org/10.11606/issn.23169087.v3i0p31-44 
VASCONCELOS, S. D.; SOUTO, E. O livro didático de ciências no Ensino Fundamental: proposta de critérios para analise do conteúdo zoológico. Ciência \& Educação, v. 9, n. 1, p. 93-104, 2003. http://dx.doi.org/10.1590/S1516-73132003000100008.

VESENTINI, J. W. A questão do livro didático no ensino da Geografia: novos caminhos da Geografia. In CARLOS, A. F. A. (Org.). Caminhos da Geografia. 5. ed. São Paulo: Contexto, 2007.

$10 \begin{aligned} & \text { Este artigo é distribuído nos termos e condições do Creative Commons Attributions/Atribuição- } \\ & \text { NãoComercial-CompartilhaIgual (CC BY-NC-SA). }\end{aligned}$ 